\title{
Surface Acoustic Wave Sensors for the Detection of Hazardous Compounds in Indoor Air ${ }^{\dagger}$
}

\author{
Meddy Vanotti 1,*, Christophe Theron ${ }^{2}$, Sacha Poisson ${ }^{1}$, Valentin Quesneau ${ }^{3}$, Mario Naitana ${ }^{3}$, \\ Valérie Soumann ${ }^{1}$, Stéphane Brandès ${ }^{3}$, Nicolas Desbois ${ }^{3}$, Claude Gros ${ }^{3}$, Thu-Hoa Tran-Thi ${ }^{2}$ \\ and Virginie Blondeau-Patissier ${ }^{1}$ \\ 1 Time and frequency Department, FEMTO-ST Institute, 26 ch. de l'Epitaphe 25030 Besançon, France; \\ sacha.poisson@univ-fcomte.fr (S.P.); valerie.soumann@femto-st.fr (V.S.); \\ virginie.blondeau@femto-st.fr (V.B.-P.) \\ 2 NIMBE, UMR 3685, CEA, CNRS, Université Paris-Saclay, CEA-Saclay, 91191 Gif-sur-Yvette, France; \\ theronchris@gmail.com (C.T.); thu-hoa.tran-thi@cea.fr (T.-H.T.-T.) \\ 3 ICMUB, UMR CNRS 6302, 9 avenue Alain Savary-BP 47870-21078 Dijon Cedex, France; \\ Valentin.Quesneau@u-bourgogne.fr (V.Q.); Mario.Naitana@u-bourgogne.fr (M.N.); \\ Stephane.Brandes@u-bourgogne.fr (S.B.); Nicolas.Desbois@u-bourgogne.fr (N.D.); \\ Claude.Gros@u-bourgogne.fr (C.G.) \\ * Correspondence: meddy.vanotti@femto-st.fr; Tel.: +33-381-402-954 \\ + Presented at the Eurosensors 2017 Conference, Paris, France, 3-6 September 2017.
}

Published: 24 August 2017

\begin{abstract}
In this work, the authors show the capabilities of Surface Acoustic Wave (SAW) devices coupled with various absorbents to probe the properties of gas sensitive materials for the manufacturing of hazardous gas sensors. The great capabilities of cobalt corroles for the trapping of carbon monoxide (CO) were exploited to produce selective sensors. These corroles were deposited on SAW delay lines surfaces and then exposed to carbon monoxide (CO) in standard conditions. Concentrations of a few hundreds of ppb were measured emphasizing the interest of such sensors for the detection of $\mathrm{CO}$. Another type of sensitive layers exhibiting specific porosity adapted to the trapping of formaldehyde $\left(\mathrm{CH}_{2} \mathrm{O}\right)$ were deposited on similar delay lines. A detection threshold of $140 \mathrm{ppb}$ was shown. These encouraging results pave the way for the development of a functionalized SAW sensors network for multi-gas detection in indoor air.
\end{abstract}

Keywords: SAW; Love waves; cobalt corroles; Nano-porous films; carbon monoxide; formaldehyde

\section{Introduction}

During the last two decades, the potential impact of indoor air quality on human health has stimulated an interest in hazardous compounds survey such as formaldehyde $\left(\mathrm{CH}_{2} \mathrm{O}\right)$ [1] and carbon monoxide (CO) [2]. Formaldehyde being a carcinogenic, the World Health Organization (WHO) recommends exposure limit as low as $80 \mathrm{ppb}$ of formaldehyde during $30 \mathrm{~min}$ [3]. The French Institute for Health Surveillance (InVS) reports that accidental domestic poisoning by the CO affects about 1000 households in France each year [4], and are responsible for about 100 deaths. The detection of these two compounds has consequently become a need. To address these needs, we here report results on the capability of functionalized Surface Acoustic Wave (SAW) devices for the selective detection of $\mathrm{CO}$ and $\mathrm{CH}_{2} \mathrm{O}$.

\section{Materials and Methods}

SAW delay lines based on Love waves, shown in Figure 1, are used to probe mass, density or elastic properties of a sensitive layer deposited on its surface. In this context, together with the 
manufacturing of the SAW device, the authors have developed sensitive layers capable of efficiently and selectively trap a target gas.

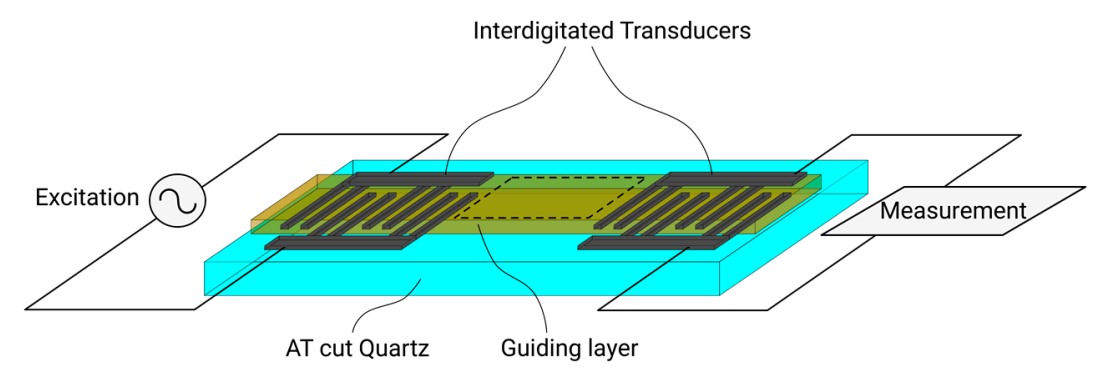

Figure 1. Structure of the SAW device used for the manufacturing of the gas sensors. These sensors are based on a delay line configuration exhibiting a free propagation path (dotted line area) where the sensitive material is deposited.

\subsection{Formaldehyde Sensor}

For the production of the $\mathrm{CH}_{2} \mathrm{O}$ sensor, two different sensitive layers were tested; a first layer referred as L1 displays a specific nano-porosity allowing the trapping of small molecules such as $\mathrm{CH}_{2} \mathrm{O}$. A second sensitive layer referred as $\mathrm{L} 2$ displays functional groups aimed at improving the molecular interaction with $\mathrm{CH}_{2} \mathrm{O}$. Both materials were produced via the sol-gel process and were deposited as thin films on the SAW device by spin-coating.

\subsection{Carbon Monoxide Sensor}

For the functionalization of the $\mathrm{CO}$ sensors, we took advantage of the great capabilities of cobalt corroles to trap this molecule [5,6]. Because of the structure of the corroles, small molecules such as $\mathrm{N}_{2}, \mathrm{O}_{2}$ and $\mathrm{CO}$ can be trapped within by mean of weak interactions. In the particular case of $\mathrm{CO}$, stronger chemical interactions are involved reaching high selectivity for this gas. The use of a variety of cobalt corroles including new structures of corroles complexes represents an innovative aspect of this work.

\section{Results}

Modifications of the physical properties of the sensitive layer consecutive to gas adsorption lead to a shift of the synchronous frequency of the delay line. Since the phase is linear with the frequency for such a device, the frequency shift can be revealed by a phase shift measurement at constant frequency. The characterization of the adsorption of the targeted pollutant onto the surface is then achieved by calculating the slope of the phase at the beginning of its decrease. This approach allows to measure concentrations of gas within a few tens of seconds.

\subsection{Formaldehyde Measurements}

As shown on Figure 2, with the first layer L1 displaying a specific porosity adapted to the trapping of $\mathrm{CH}_{2} \mathrm{O}$, a drift of the signal in the presence of $\mathrm{N}_{2}$ used as a carrier gas is observed indicating that $\mathrm{N}_{2}$ molecules are also adsorbed in the nano-porous layer. This lack of selectivity induces a weak sensitivity of the sensor to $\mathrm{CH}_{2} \mathrm{O}$. As a matter of fact, it enables the detection of $\mathrm{CH}_{2} \mathrm{O}$ only at concentrations superior or equal to $2.5 \mathrm{ppm}$ which do not fit with the required WHO detection threshold.

Based on these results, the second functionalized sensitive layer $\mathrm{L} 2$ was used to enhance $\mathrm{CH}_{2} \mathrm{O}$ adsorption at the expense of $\mathrm{N}_{2}$ adsorption. One can see in Figure 3a that with L2, the drift caused by the exposure to $\mathrm{N}_{2}$ is substantially reduced and the sensitivity is strongly improved, allowing the detection of $\mathrm{CH}_{2} \mathrm{O}$ at concentrations as low as $80 \mathrm{ppb}$ with a sensitivity of $2.6 \mathrm{e}^{-3}{ }^{\circ} \cdot \mathrm{s}^{-1} \cdot \mathrm{ppm}^{-1}$. 


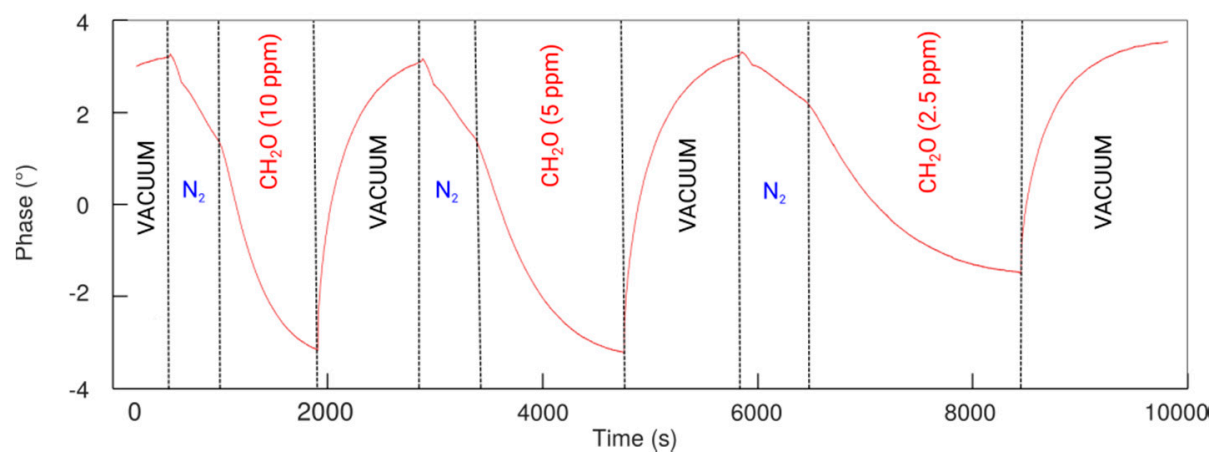

Figure 2. Measurements of $\mathrm{CH}_{2} \mathrm{O}$ concentrations with $\mathrm{SAW}$ devices functionalized with sensitive layer L1.

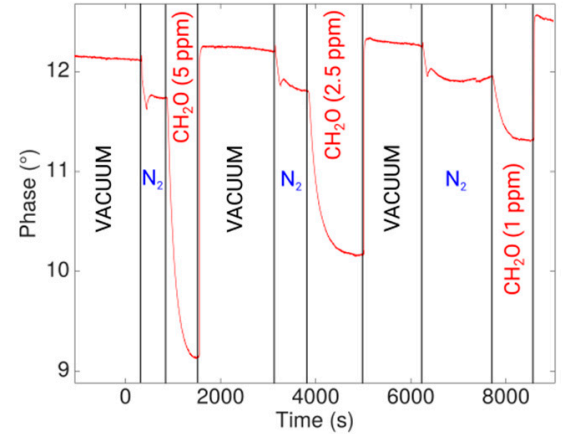

(a)

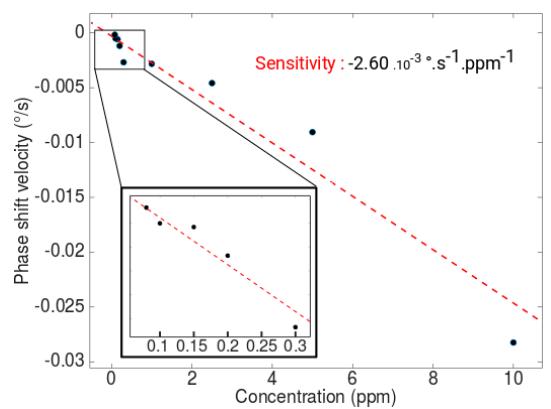

(b)

Figure 3. (a) Measurements of $\mathrm{CH}_{2} \mathrm{O}$ concentration with $\mathrm{SAW}$ devices functionalized with sensitive layer L2; (b) The correlation between the phase shift velocity during the exposure and the concentration of $\mathrm{CH}_{2} \mathrm{O}$.

\subsection{Carbon Monoxide Measurements}

SAW delay line covered with new structures of corroles was exposed to $\mathrm{CO}$ at low concentration. Figure 4 a represents the sensor response to CO diluted in $\mathrm{N}_{2}$ in the $10 \mathrm{ppm}$ to $200 \mathrm{ppb}$ range. This sensor has shown a great sensitivity to $\mathrm{CO}$ allowing the detection of concentration as low as $200 \mathrm{ppb}$. One can see a drift of the signal following the detection. This behavior is attributed to temperature changes when shifting from the carrier gas to the target gas. In order to address a response to that issue, a second delay line used as a temperature reference is currently under development. Figure $4 \mathrm{~b}$ shows that despite of the temperature-related measurement problems, the signals observed are correlated to the CO concentration with a sensitivity of $1.32 \mathrm{e}^{-3}{ }^{\circ} \cdot \mathrm{s}^{-1} \cdot \mathrm{ppm}^{-1}$.

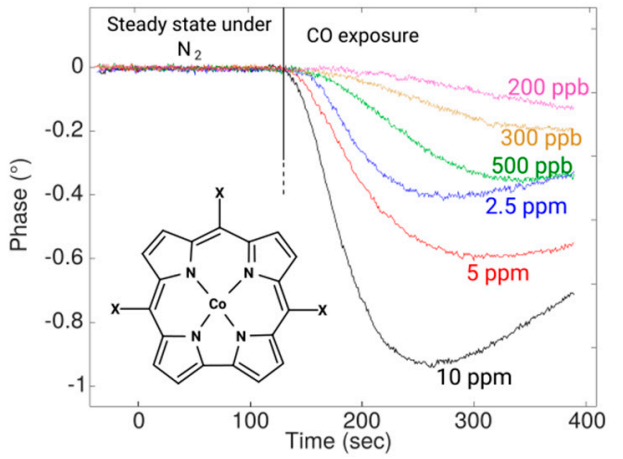

(a)

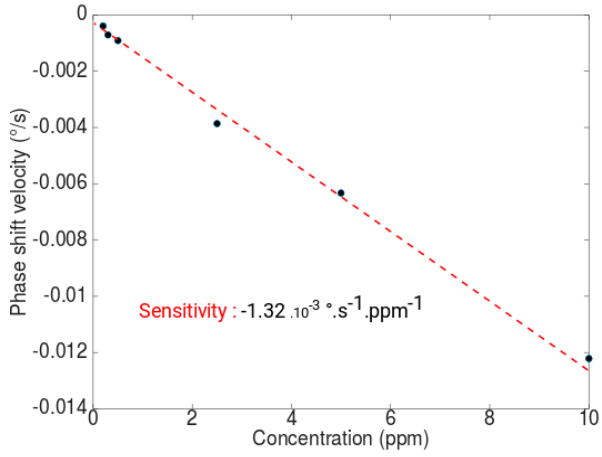

(b)

Figure 4. (a) Responses in phase of a functionalized SAW device to carbon monoxide in the $10 \mathrm{ppm}$ to $200 \mathrm{ppb}$ range; (b) Correlation between the phase shift velocity during the exposure and the concentration of carbon monoxide. 


\section{Conclusions}

A linear correlation between the phase shifts velocity of the Love wave and the target gases concentrations has been demonstrated. The experiments have been repeated several times to validate the results under various concentrations. It was shown that the use of Love wave devices functionalized with sensitive materials such as corrole complexes or nano-porous layers enable gas detection at concentrations as low as a few tens of $\mathrm{ppb}$ for $\mathrm{CH}_{2} \mathrm{O}$ and a few hundreds of $\mathrm{ppb}$ in the case of $\mathrm{CO}$. These results pave the way to investigating other gas detection with specific functionalized acoustic waves devices.

Acknowledgments: The authors are grateful to the French National Research Agency (ANR CO3SENS project) and to bpi-France (SMARTY project $\mathrm{N}^{\circ} 165022$ ) for their financial supports. V. Quesneau also thanks the "Region Bourgogne" for providing his PhD grant. This work was also partly supported by the French RENATECH network and its FEMTO-ST technological facility.

Conflicts of Interest: The authors declare no conflict of interest.

\section{References}

1. Kim, W.J.; Terada, N.; Nomura, T.; Takahashi, R.; Lee, S.D.; Park, J.H.; Konno, A. Effect on formaldehyde on the expression of adhesion molecule in nasal microvascular endothelial cells: The role of formaldehyde in the pathogenesis of sick building syndrome. Clin. Exp. Allergy 2002, 32, 287-295.

2. Raub, J.A.; Mathieu-Nolf, M.; Hampson, N.B.; Thom, S.R. Carbon monoxide poisoning-A public health perspective. Toxicology 2000, 145, 1-14.

3. Krzyzanowski, M.; World Health Organization-Regional Office for Europe. New guidelines for selected indoor chemicals establish targets at which health risks are significantly reduced, Fact sheet, 15 December 2010.

4. Christophe, L.; Ménard, C.; Verrier, A.; Arwidson, P.; du Roscoät, E. Carbon monoxide: analysis of perceptions, knowledge and behaviors of intoxicated household referents during the heating season 2013-2014 in France. Bull. Epidémiol. Hebd. 2015, 2016, 89-96.

5. Guilard, R.; Gros, C.P.; Bolze, F.; Jérôme, F.; Ou, Z.; Shao, J.; Fischer, J.; Weiss, R.; Kadish, K.M. Alkyl and Aryl Substituted Corroles. 1. Synthesis and Characterization of Free Base and Cobalt Containing Derivatives. X-ray Structure of ( $\mathrm{Me}_{4} \mathrm{Ph}_{5} \mathrm{Cor}$ ) Co (py)2. Inorg. Chem. 2001, 40, 4845-4855.

6. Barbe, J.-M.; Canard, G.; Brandès, S.; Jerôme, F.; Dubois, G.; Guilard, R. Metallocorroles as sensing components for gas sensors: remarkable affinity and selectivity of cobalt(III) corroles for $\mathrm{CO}_{\text {vs. }} \mathrm{O}_{2}$ and $\mathrm{N}_{2}$. Dalton Trans. 2004, 8, 1208-1214.

(C) 2017 by the authors. Licensee MDPI, Basel, Switzerland. This article is an open access article distributed under the terms and conditions of the Creative Commons Attribution (CC BY) license (http://creativecommons.org/licenses/by/4.0/). 